\title{
On-site veterinary and sanitary examination of emergency slaughtered poultry
}

\author{
I.G. Seregin ${ }^{1}$, V.E. Nikitchenko ${ }^{1,}$, D.V. Nikitchenko ${ }^{1}$, G.V. Snoz ${ }^{2}$ and K.M. Kondrashkina ${ }^{1}$ \\ ${ }^{1}$ Peoples' Friendship University of Russia, 117198, Moscow, Russia \\ ${ }^{2}$ Federal State Budgetary Educational Institution of Higher Education «Moscow State Academy of \\ Veterinary Medicine and Biotechnology - MVA named after K.I. Skryabin», 109472, Moscow, \\ Russia
}

\begin{abstract}
The paper reports the veterinary culling rates and emergency slaughter statistics at poultry factories; it also analyses the veterinary and sanitary quality of carcasses of culled poultry in comparison to that of a healthy population. This analysis identifies organoleptic, physical, chemical, and microbiological differences between the two categories of meat. Finally, based on this data, the paper draws recommendations on the most optimal and safe use of meat produced by emergency slaughter.
\end{abstract}

\section{Introduction}

Poultry is traditionally farmed in Russia for eggs and meat. Chicken eggs and meat are valuable foods for people of any age. Moreover, these are the most accessible foods for Russians, both physically and economically. Poultry meat is mainly sold in carcasses, halfcarcasses, and as a variety of semi-finished products [1].

It is perishable food, which means poultry factories cannot store it unfrozen for more than five days of slaughter. Therefore, retailers should only receive the meat of healthy poultry that will not spoil over five days. Furthermore, whether cultivating poultry in cages or on the floor in an industrial setting, farmers seek to maximize space utilization - highdensity results in higher incidence rates of infectious and non-infectious diseases. Therefore, when seeming sick, poultry is usually subject to culling and slaughter [2]. Unfortunately, culled poultry is often slaughtered as if it was healthy, and its meat goes into processing and retail. Besides, there are cases of selling emergency slaughtered poultry as grilled or semi-finished meat products [3].

According to Guidelines for Veterinary Inspection of Meat-Producing Animals, Veterinary and Sanitary Examination of Meat and Meat Products, poultry of various species and ages are allowed for slaughter if their clinical status is normal. Only in some cases, sick or culled poultry may be subject to emergency slaughter upon the State Veterinary Service's permission $[4,5]$.

Subject to emergency slaughter is poultry suffering acute or chronic diseases that either (i) cannot be treated effectively; or (ii) will require complicated and cost-ineffective prevention and treatment [6]. Poultry farms and private farmers are also often forced to

\footnotetext{
*Corresponding author: rystsova-eo@pfur.ru
} 
slaughter poultry that has been severely injured and sustained grave organ damage has bone fractures, or signs of profound metabolic disorders, as well as poultry that has been culled for other veterinary reasons, including the elimination of infectious and invasive diseases. Culling and slaughter for breed-, age-, productivity-related, or sundry zootechnical or economic reasons are not within the definition of emergency slaughter. This poultry is often slaughtered together with healthy specimens. Killing specimens in agony or clinical death is not an emergency slaughter either. In such cases, meat is not used for food; instead, it is utilized to produce dry pet feed or other products unless disposed of $[7,8]$.

Veterinary service specialists determine the emergency slaughter procedure; to that end, they should inspect the poultry, compile the culling act, and order emergency slaughter subject to specific hygiene requirements. Emergency slaughter must be done at the sanitation facility or the slaughterhouse at the end of the shift or on a specially designated day. The large-scale emergency slaughter of livestock and poultry at homes is either banned or subject to the State Veterinary Service's permit and control.

In the EU, retailers can sell meat produced from emergency slaughtered poultry for human consumption if the slaughter was performed on the grounds of minor mechanical injuries, and the veterinarian had not found any clinical symptoms of a disease before slaughter. A declaration must be made for the carcass of emergency-slaughtered poultry if it is to be sold later (Regulation (EC) No. 853/2004) [9]. A post-slaughter examination is to be performed in compliance with the Directive (EU) 854/2004; any additional investigation might be prescribed in case of emergency slaughter. Meat produced from emergency slaughtered animals can be sold subject to having unique markings presented in the Directive (EU) 854/2004 only in the state where such slaughter took place [10]. In South Africa, they cleaned the meat and sold it frozen only if the emergency slaughter was necessitated by minor mechanical injuries $[11,12]$.

There are many possible reasons for emergency slaughter, making processing meat of limited usability an important social issue that calls for veterinarians' attention. At the same time, poultry factories have recently been slaughtering less and less poultry culled due to veterinary or sanitary defects, and processing facilities are being supplied less such meat, with many not receiving emergency slaughtered poultry at all. However, Russian households and farms still cull up to $20-25 \%$ of the entire stock; the culling rates, especially for cases of non-infectious diseases, remain high, which calls for investigation into the issues of scientifically sound veterinary and sanitary inspection of carcasses and offal of emergency slaughtered poultry, which was the reason to conduct this research $[8,13,14]$.

\section{Materials and Methods}

The goal hereof was to comparatively analyse the veterinary and sanitary parameters of healthy poultry vs. culled/emergency slaughtered populations. To that end, the authors scored the meat of chickens and cockerels culled for Salmonella, leukaemia, tuberculosis, pseudomonas, peritonitis, injuries, and metabolic disorders, in terms of organoleptic, physics, chemistry, and microbiology; the scores were compared to those of healthy poultry grown at the same factory.

The food quality indicators were measured per GOST 31962-20 Chicken meat (carcasses of chickens, broiler chickens, and their parts). Specifications. Organoleptic, physical, and chemical tests were carried out per GOST R 51944-2002 Poultry meat. Methods for determining organoleptic properties, temperature, and mass; GOST 314702012 Poultry meat, edible offal, and semi-processed products. Techniques for organoleptic and physicochemical examinations and Guidelines for Veterinary Inspection of MeatProducing Animals, Veterinary and Sanitary Examination of Meat and Meat Products (1988). 
Microbiological tests followed GOST R 50396.0-2013 Poultry meat, edible offal, and semi-prepared products from poultry meat. Sampling methods and preparing for microbiological examinations; GOST R 50396.1-2010; GOST 30726-2001; GOST R 54374-2011; GOST 31468-2012; GOST 7702.2.7-2013; GOST 7702.2.6-93; GOST R 54674-2011; GOST 32031-2012, and Guidelines for Sanitary and Microbiological Control of Poultry Carcasses, Meat, Eggs, and Egg Products at Poultry Farms and Processing Factories (1990).

Experimental and control chicken meat was tested for safety per Guidelines for Rapid Toxicity Detection in Livestock Products and Feeds as approved by the Veterinary Department of the Russian Ministry of Agriculture on October 16, 2000, No. 13-7-2/2156. In addition, relative biological value (RBV) was determined per Guidelines for Fast Biological Valuation of Products and Feeds as approved by VASKhNIL, 1990.

\section{Results and Discussion}

The first step was to analyse the culling rates of broilers and laying hens. Monthly culling rates were found from veterinary service logs. It turned out they had been culling $4.7 \%$ to $7.8 \%$ of broilers aged $42-49$ days every month for a variety of reasons. Chicks were mainly culled for mechanical injuries and metabolic disorders. From $0.4 \%$ to $2.8 \%$ of laying hens were culled due to metabolic disorders, yolk peritonitis, and mechanical injuries. From $0.27 \%$ to $4.9 \%$ of broilers were culled for infections. According to the Veterinary Sanitary Inspection Guidelines, culled poultry must be registered as sick or suspected sick and further slaughtered subject to specific sanitary requirements and restrictions. The authors hereof compared the food quality indicators of culled and healthy poultry (Table 1).

Table 1. Food quality indicators of emergency slaughtered vs. healthy poultry carcasses.

\begin{tabular}{|c|c|c|c|}
\hline \multirow{2}{*}{ Indicator } & \multicolumn{2}{|c|}{ Carcass average } & \multirow{2}{*}{ Difference } \\
\cline { 2 - 3 } & culled & healthy & \\
\hline Live weight, g & $1880 \pm 42.5$ & $2260 \pm 67.0$ & -380 \\
\hline Cat. 1 nutritional status, \% & $43.6 \pm 0.32$ & $79.5 \pm 0.58$ & -35.9 \\
\hline Kill out percentage, \% & $65.8 \pm 0.82$ & $70.4 \pm 0.76$ & -4.6 \\
\hline Meat yield, \% & $55.2 \pm 0.61$ & $58.8 \pm 0.61$ & -3.6 \\
\hline Bone yield, \% & $41.8 \pm 0.46$ & $39.4 \pm 0.42$ & +2.4 \\
\hline White muscle yield, \% & $55.2 \pm 0.51$ & $57.4 \pm 0.63$ & -2.2 \\
\hline Red muscle yield, \% & $37.5 \pm 0.42$ & $39.6 \pm 0.38$ & -2.1 \\
\hline Fat content, \% & $7.1 \pm 0.07$ & $9.8 \pm 0.09$ & -2.7 \\
\hline Carcass weight loss in maturation, \% & $1.3 \pm 0.11$ & $1.2 \pm 0.11$ & +0.1 \\
\hline Bleeding rate, points & $6.9 \pm 0.08$ & $7.4 \pm 0.09$ & -0.5 \\
\hline Process-related waste, \% & $13.6 \pm 0.17$ & $11.8 \pm 0.13$ & +1.8 \\
\hline
\end{tabular}

Emergency slaughtered poultry had a $380 \mathrm{~g}$ lower average live weight than its healthy counterparts. $79.5 \pm 0.58 \%$ of the healthy poultry yielded Category 1 carcasses, while the exact figure for culled poultry was only $43.6 \pm 0.32 \%$ or $35.9 \%$ lower. The Kill-out percentage was $4.6 \%$ lower in culled chickens compared to the healthy ones. The meat yield was $55.2 \pm 0.61 \%$ in culled poultry, $58.8 \pm 0.61 \%$ or $3.6 \%$ more significant in the healthy subpopulation. At the same time, the sick poultry had a $2.4 \%$ higher bone yield.

Meanwhile, the white muscle yield was $2.2 \%$ lower in sick chickens than in their healthy counterparts. The red muscle weight and the fat content were lower, too, by $2.1 \%$ and $2.7 \%$, respectively. Other negative factors included 0.5 points lower bleeding rate and 1.8 p.p. more process-related waste. Thus, the analysis shows that culled and emergency 
slaughtered poultry has less live weight, worse nutritional status, lower kill-out percentage, meat yield, and fat content. In addition, they produce more bones and process-related waste while losing more weight in storage.

Organoleptic tests on a 9-point scale returned 0.6 to 1.2 points lower results for sick poultry. The difference was most pronounced in terms of colour, odor, and taste. Healthy poultry got 7.9 to 8.4 points across the board, while the emergency slaughtered subpopulation got 7.4 to 7.8 at max.

Specific differences were found in the chemical composition of healthy and sick poultry. Table 2 shows the chemical indicators.

Table 2. Chemical composition of muscles in emergency slaughtered and healthy poultry.

\begin{tabular}{|c|c|c|c|}
\hline \multirow{2}{*}{ Indicator } & \multicolumn{2}{|c|}{ Meat test results } & \multirow{2}{*}{ Difference } \\
\cline { 2 - 3 } & healthy (control) & culled & \\
\hline \multicolumn{3}{|c|}{ 1. Chemical composition of breast muscles } \\
\hline Moisture content, wt.\% & $71.06 \pm 0.82$ & $73.16 \pm 0.83$ & +2.10 \\
\hline Protein, \% & $21.68 \pm 0.36$ & $20.62 \pm 0.31$ & -1.06 \\
\hline Fat, \% & $3.69 \pm 0.03$ & $2.89 \pm 0.04$ & 0.80 \\
\hline Ash, \% & $1.03 \pm 0.02$ & $1.01 \pm 0.02$ & -0.02 \\
\hline Extractives & $2.54 \pm 0.03$ & $2.32 \pm 0.03$ & -0.22 \\
\hline \multicolumn{3}{|c|}{ 2. Chemical composition of thigh muscles } \\
\hline Moisture content, wt.\% & $70.97 \pm 0.68$ & $72.77 \pm 0.96$ & +1.80 \\
\hline Protein, \% & $19.44 \pm 0.22$ & $19.12 \pm 0.27$ & 0.32 \\
\hline Fat, \% & $5.09 \pm 0.47$ & $4.07 \pm 0.60$ & -1.02 \\
\hline Ash, \% & $1.07 \pm 0.02$ & $1.01 \pm 0.02$ & -0.06 \\
\hline Extractives & $3.43 \pm 0.03$ & $3.03 \pm 0.04$ & -0.40 \\
\hline
\end{tabular}

The table shows that emergency slaughtered poultry's muscles had $1.8 \%$ to $2.1 \%$ more moisture but $0.32 \%$ to $1.06 \%$ less protein, 0.80 to 2.02 less fat, and $0.22 \%$ to $0.42 \%$ fewer extractives. Ash content did not differ significantly. The chemistry of thigh muscles in sick chickens had more pronounced deviations than red meat in healthy birds. The moisture content was $72.77 \pm 0.96 \mathrm{wt} . \%$ in the red meat in sick poultry, $70.97 \pm 0.68 \mathrm{wt} \% \%$ in the thigh muscles of healthy laying hens.

The pronounced difference was also observed in the physical and chemical indicators. Thus, culled poultry meat had higher $\mathrm{pH}$ and more frequent abnormalities in reactions to copper sulfate and peroxidase in volatile fatty acid and amino-ammoniacal nitrogen and the acid and peroxide value of fat. As a rule, all these indicators were worse in sick poultry. Thus, the difference in $\mathrm{pH}$ was 0.45 to 0.49 compared to the controls, the difference in the acid value of fat was 0.12 to $0.14 \mathrm{mg} \mathrm{KOH}$, and the difference in volatile fatty acids was 0.29 to $0.34 \mathrm{mg} \mathrm{KOH}$, while the water-binding capacity differed by $4.79 \%$ to $5.90 \%$ See Table 3 for the data.

Table 3. Physical and chemical indicators of culled poultry meat.

\begin{tabular}{|c|c|c|c|}
\hline \multirow{2}{*}{ Indicator } & \multicolumn{2}{|c|}{ Meat test results } & \multirow[b]{2}{*}{ Difference } \\
\hline & healthy & culled & \\
\hline \multicolumn{4}{|c|}{ 1. White meat test results } \\
\hline $\mathrm{pH}$ & $6.02 \pm 0.01$ & $6.47 \pm 0.02$ & +0.45 \\
\hline Reaction to peroxidase & positive & doubtful & pronounced \\
\hline Reaction to copper sulfate & negative & doubtful & pronounced \\
\hline reaction to hydrogen sulfide & negative & negative & $\begin{array}{c}\text { no } \\
\text { difference }\end{array}$ \\
\hline Response to Nessler's reagent & negative & negative & $\begin{array}{c}\text { no } \\
\text { difference } \\
\end{array}$ \\
\hline
\end{tabular}




\begin{tabular}{|c|c|c|c|}
\hline The acid value of fat, $\mathrm{mg} \mathrm{KOH}$ & $0.38 \pm 0.04$ & $0.56 \pm 0.06$ & +0.12 \\
\hline Volatile fatty acids, mg KOH & $1.56 \pm 0.16$ & $1.90 \pm 0.27$ & +0.34 \\
\hline Water-binding capacity, $\%$ & $42.30 \pm 0.29$ & $36.40 \pm 0.27$ & -5.90 \\
\hline \multicolumn{4}{|c|}{ 2. Red meat test results } \\
\hline $\mathrm{pH}$ & $6.30 \pm 0.09$ & $6.79 \pm 0.07$ & +0.79 \\
\hline Reaction to peroxidase & positive & doubtful & pronounced \\
\hline Reaction to copper sulfate & negative & doubtful & pronounced \\
\hline reaction to hydrogen sulfide & negative & negative & no difference \\
\hline Response to Nessler's reagent & negative & negative & no difference \\
\hline The acid value of fat, $\mathrm{mg} \mathrm{KOH}$ & $0.42 \pm 0.03$ & $0.56 \pm 0.06$ & +0.14 \\
\hline Volatile fatty acids, mg KOH & $1.62 \pm 0.09$ & $1.91 \pm 0.09$ & +0.29 \\
\hline Water-binding capacity, $\%$ & $40.91 \pm 0.41$ & $36.12 \pm 0.32$ & -4.79 \\
\hline
\end{tabular}

Microbiological tests showed a 2.1 to 3.2 times higher microbial contamination of meat in emergency slaughtered poultry. The value was $0.24-0.39 * 10^{2}$, and $4.7-7.1 * 10^{2}$ in healthy and emergency slaughtered poultry, respectively. Some of the samples of the latter contained E. coli and Salmonella. No other pathogens, including Listeria monocytogenes and infectious agents, were found. See Table 4 for the data.

Table 4. Microbiological test results.

\begin{tabular}{|c|c|c|c|}
\hline \multirow{2}{*}{ Bacteriological tests } & \multicolumn{2}{|c|}{ Meat test results } & \multirow{2}{*}{ Difference } \\
\cline { 2 - 3 } $\begin{array}{c}\text { Bacterial cell count per } \\
\text { field }\end{array}$ & 1 to 3 bacterial cells & 9 to 13 bacterial cells & \multirow{2}{*}{+8 bacterial cells } \\
\hline MAFAM, CFU/g & $(0.24-0.29) * 10^{2}$ & $(4.1-4.9) * 10^{2}$ & $+3.61-3.86$ \\
\hline E. coli & 0 & \pm & \pm \\
\hline Cl. perfringes & - & - & - \\
\hline Staph. Aureus & - & \pm & \pm \\
\hline List. monocytogenes & - & - & - \\
\hline Proteus Vulgaris & - & - & \pm \\
\hline Saprophytes & \pm & + & culled \\
\hline
\end{tabular}

Increased microbial contamination led to faster spoiling in storage. When chilled, the meat from emergency slaughtered poultry showed signs of spoilage 1 to 2 days earlier than healthy meat.

Emergency slaughtered poultry meat had $6.4 \%$ to $7.6 \%$ worse biological value and safety readings of the experiments on Tetrahymena pyriformis compared to meat from healthy poultry. Infusoria cell growth in a nutrient medium was 44.8-47.9*104 per ml when using healthy poultry meat extract, $41.1-44.0 * 104$ in emergency slaughtered poultry, or 3.7$3.9 * 104 / 7.6 \%$ lower. This should be borne in mind when processing meat from emergency slaughtered poultry.

\section{Conclusion}

Collected data suggests that the meat of emergency slaughtered poultry differs from that of healthy birds in organoleptic, physical, chemical, and microbiological indicators and biological value, as shown in infusoria experiments.

Compared to healthy poultry's meat, that produced from emergency slaughtered animals had lower quality scores. It contained more moisture and less protein, fat, and extractives. The fat had a higher acid value. In terms of water retention and biological value, it was $4.72 \%$ to $5.50 \%$ and $6.4 \%$ to $7.6 \%$ worse, respectively. In addition, meat produced by emergency slaughter spoiled faster when stored chilled. 
Due to possible E. coli and Salmonella contamination, emergency slaughtered poultry meat should not be sold freely or used to make semi-finished products. Instead, it is subject to laboratory tests or industrial processing at higher temperatures or preliminary decontamination by cooking. As a result, such meat has lower organoleptic and food quality scores. In addition, it shows signs of biochemical and microbiological spoilage faster; all of this should be kept in mind when storing and processing carcasses.

After decontamination, it can be used to produce cooked sausages or canned meat. However, if there are pathological changes in bodies or muscles, such meat must be disposed of.

When processing meat of emergency slaughtered poultry, the facility is subject to veterinary and sanitary measures to remove E.coli, Salmonella, and sundry microorganisms found in poultry from the equipment.

\section{References}

1. S.S. Kozak, Veterinaria Kormlenie 2, 46-49 (2016)

2. EFSA AHAW Panel (EFSA Panel on Animal Health and Welfare), EFSA Journal 11(12), 3460 (2013)

3. I.G. Seregin, Meat Technology 6, 37-42 (2018)

4. M.P. Butko, P.A. Popov, S.A. Lavina, I.S. Osipova, Ye.A. Semenova, Problems on Veterinary Sanitation, Hygiene, and Ecology 1(25), 38-43 (2018)

5. V.V. Gushchin, I.I. Makoveev, V.S. Bragin, A.L. Makoveeva, Ptitsevodstvo 7, 37-40 (2016)

6. HAS, Practical Slaughter of Poultry: A Guide for the Small Producer, Wheathampatead, UK (2004)

7. V.I. Dorozhkin, M.P. Butko, A.S. Gerasimov, T.F. Pokornaya, V.I. Belousov, Problems on Veterinary Sanitation, Hygiene and Ecology 1(17), 6-16 (2018)

8. I.G. Seregin, V.Ye. Nikitchenko, D.V. Nikitchenko, RUDN Journal of Agronomy and Animal Industries 1(13), 61-69 (2018)

9. Corrigendum to Regulation (EC) No. 853/2004 of the European Parliament and of the Council of April 29, 2004, laying down specific hygiene rules for food of animal origin

10. Corrigendum to Regulation (EC) No. 854/2004 of the European Parliament and of the Council of April 29, 2004, laying down specific rules for the organisation of official controls on products of animal origin intended for human.

11. I.G. Seregin, Ye.S. Baranovich, T.V. Kurmakayeva, M.L. Gusarov, BIO 6 (225), 14-17 (2019)

12. The Department of Agriculture, Forestry, and Fisheries of the Republic of South Africa. Poultry meat inspection manual of January 2007

13. S.S. Kozak, I.V. Mokshantseva, Yu.A. Kozak, Veterinaria i Kormlenie 2, 55-58 (2018)

14. Order of the Ministry of Agriculture (Minselkhoz) of Russia No. 72 dd. March 12, 2014. On Approval of Veterinary Guidelines for Animal Slaughter and Primary Processing of Meat and Sundry Non-Industrial Slaughter Products at Low- and Medium-Capacity Slaughterhouses 